\title{
The evaluation of a continuing professional development package for primary care dentists designed to reduce stress, build resilience and improve clinical decision-
}

making.

Helen R Chapman $\left(1,2^{*}\right)$ MSc, BDS

Susan Y Chipchase (3) BSc, MSc, PhD

Roger Bretherton (4) BSc, DClinPsy

1. Paul Lowe Dentistry, 31 Farmhouse way, Monkspath, Solihull B90 4EH

2. Visiting Fellow, School of Psychology, University of Lincoln, Brayford Pool, Lincoln LN6 7TS

3. Senior Lecturer, School of Psychology, University of Lincoln, Brayford Pool, Lincoln LN6 7TS

4. Principal Lecturer (Enterprise), School of Psychology, University of Lincoln, Brayford Pool, Lincoln LN6 7TS

${ }^{*}$ Correspondence to: Mrs Helen Chapman email: hchapman@lincoln.ac.uk 


\begin{abstract}
Introduction: Stress and burnout are widely accepted as a problem for primary care dental practitioners. Previous programmes to address this issue have met with some success. Burnout is associated with poor coping skills and emotion regulation, and increased rates of clinical errors. Anxiety is associated with poor decision-making and is thought to be associated with poor clinical decision-making. Attempts to improve decision-making use increasing meta-awareness and review of thinking processes. Bibliotherapy is an effective method of delivering cognitive behavioural therapy as self-help or guided self-help (with some therapist input) formats.
\end{abstract}

Objective: To evaluate the efficacy of a specially designed CPD package which was designed to improve coping skills, build resilience and reduce the impact of anxiety on dentists' clinical decision-making.

Design: A multi-centred quasi-experiment

Setting: Lincolnshire and Nottinghamshire (England) 2014

Materials and methods: Thirty-five volunteer primary care dentists used two versions (selfhelp [SH] and guided self-help [GSH], which included a 3 hour workshop) of a specially written cognitive-behavioural-therapy bibliotherapy programme designed to improve wellbeing and decision-making.

Main Outcome Measures: The main outcome measures were dentists' burnout, depression, anxiety, stress and decision-making style. Data were also collected on use and evaluation of the programme.

Results: At 6 weeks there was a clinically and statistically significant reduction in depression, anxiety and stress levels, a statistically significant reduction in burnout (emotional exhaustion) and hypervigilant decision-making and an increase in personal achievement (burnout). The improvements in depression, stress, emotional exhaustion and hypervigilant decision-making were maintained at 6 months. Dentists were overwhelmingly positive in their evaluation of the project and used most of its contents.

Conclusion: With the caveat of small numbers and the lack of a no-treatment control, this project demonstrated that a self-help package can be highly acceptable to dentists and, in the short-to-medium term, improve dentists' well-being and decision-making with implications for patient safety. 


\section{Introduction}

\section{Burnout}

Stress and burnout are a well-established problem for primary care dentists both nationally ${ }^{1-3}$ and internationally. ${ }^{4-7}$ Recent research suggests that rates of burnout vary between $8 \%{ }^{3}$ in the UK and approximately $16 \%$ in the Netherlands ${ }^{7}$ and that rates appear to be rising. ${ }^{7}$ Burnout is a response to the chronic emotional strain of dealing with people, particularly if they have problems. ${ }^{8}$ There are 3 aspects to burnout; ${ }^{9}$ emotional exhaustion (EE; feelings of being emotionally overwhelmed and exhausted by work), depersonalisation (DP; a cynical, detached feeling towards patients/clients) and a reduced sense of personal achievement (PA; one's sense of professional competence and success). There are multiple factors associated with the development of burnout including workload, control, monetary reward, social stressors (including from patients) and personal values. ${ }^{10}$

The consequences for dentists of burnout and/or the associated occupational stress include ${ }^{11,12}$ poorer mental health, physical health, a reduced likelihood of engaging in positive health-related behaviours (exercise and eating a healthy diet) and an increase in unhealthy behaviours (increased consumption of alcohol). ${ }^{12}$

Burnout appears to be related to deficits in executive functioning or cognitive control ${ }^{13}$ (working memory, reasoning, problem solving, planning and execution). Clinician (physician and surgeon) burnout can affect the quality and safety of patient care including rates of medical errors, ${ }^{14,15}$ presumably mediated by effects on executive function. There appears to be a dose-response relationship between the factors. ${ }^{16}$ However, self-reported medical errors are associated with a subsequent worsening of all domains of burnout, suggesting that a vicious circle may be in action. ${ }^{15}$ The cognitive deficits associated with burnout appear to persist beyond apparent clinical recovery and return to work. ${ }^{17}$ This has profound implications for patient safety. There appears to be no research objectively linking burnout and levels of patient complaints/clinical errors in dentists. However, a sample of dentists in the Netherlands ${ }^{12}$ reported that they believed that the health problems they reported (and which were associated with burnout scores) were associated with diminished professionalism and difficulty in concentrating, suggesting that a similar cycle of burnout and impaired cognitive function may have been operating.

There is very limited experimental evidence ${ }^{18}$ of the effects of stress on intra-operative care. What there is suggests that stress affects performance in surgeons (in particular during highly stressful laparoscopic procedures); that experienced surgeons experience less stress and are consequently less impaired, and that stress impairs surgeons' non-technical skills such as decision-making and communication skills. A recent study ${ }^{19}$ of primary care dentists found that an increased sense of PA and increased levels of EE and DP were related to higher levels of self-reported anxiety in clinical situations suggesting that reducing burnout improves decision-making and thus should improve patient outcomes.

\section{Decision-making}

Janis and Mann ${ }^{20}$ developed a generic analysis of various styles of decision-making which individuals were prone to use under varying degrees of stress such as increased time pressure. Decisional or cognitive conflict (the simultaneous opposing tendency to accept and reject a course of action) results in hesitation, vacillation, feelings of uncertainty and emotional stress which become acute when the decision-maker is aware of the potential losses of a particular course of action. This model is described in some detail elsewhere with regards to dentistry. ${ }^{19}$ Previous research ${ }^{19}$ has found that self-reported anxiety in response to typical dental stressors is significantly related to hypervigilant and avoidant decisionmaking and burnout. This would suggest that reductions in the chronic stress experienced by 
dentists should reduce unhelpful styles of decision-making and could reduce vulnerability to burnout.

Errors in clinical decision-making in the fields of medicine and surgery have been widely discussed, particularly in relation to diagnostic errors. Croskerry ${ }^{21}$ has developed a model of the aetiology of diagnostic errors and this allows for the impact of 'affective states' - anxiety disorders and mood disorders such as depression - on diagnosis. This model appears to have been the subject of limited empirical evaluation. ${ }^{22}$ Poor decision-making processes have been found to lead to poor patient outcomes. ${ }^{23}$ Therefore, this model also suggests that building resilience, with a consequent reduction in stress, anxiety and/or depression, should improve decision-making.

More specifically, Croskerry ${ }^{24}$ proposes that many, if not most, diagnostic clinical decisionmaking errors are linked to heuristic or intuitive decision-making processes rather than to planful, rational-analytic decision-making such as working through a surgical sieve. The former are subject to numerous biases ${ }^{25}$ or cognitive and affective dispositions (including stress) to respond. Heuristic decisions are more likely in times of stress. ${ }^{21}$ There have been many papers promoting conscious awareness of cognitive processes (metacognition) aimed at reducing heuristic decision-making and thereby reducing diagnostic error. However, there is very little empirical evidence that this is effective and it is therefore controversial. ${ }^{26,27}$ However, it might be argued that this is 'the best model we have' at present. A variety of educational techniques to improve clinical reasoning have been researched in general medicine and surgery with mixed results. ${ }^{28}$ Therefore, education should be capable of alerting clinicians to the possibility that decision-making may be affected whilst stressed and thus help them to stop and consider if their diagnostic process has been appropriate and safe; a process of metacognitive review.

\section{Resilience}

The concept of psychological resilience is increasingly recognised as important in preventing and 'treating' stress and burnout. It is considered to be a personality characteristic and was originally conceived as applying to children who continue to develop normally despite longterm stress or adversity. ${ }^{29}$ Resilience is carried forward into adulthood. ${ }^{30}$ There is a considerable amount of research into this phenomenon in adults. Resilient individuals appear to cope more flexibly, using a variety of coping methods, rather than relying on a narrow range of skills. ${ }^{31}$ Resilient individuals are able to accurately identify what is stressful, realistically appraise his/her capacity for action and problem solve effectively. This results in repeated mastery experiences which promote a sense of competence when facing further problems. Thus stress is moderated and adaptation promoted:32 the ability to withstand stressors is increased. ${ }^{33}$ It is protective against psychological illness. ${ }^{30}$ Current research increasingly explores the links between resilience and positive emotions; ${ }^{34}$ the broaden and build model ${ }^{35}$ in which the experience of positive emotions promotes the ability to "bounceback' ${ }^{36}$ and thrive (grow stronger).

Previous research regarding the coping skills of dentists ${ }^{1,2,37}$ found that dentists were successful at using behavioural coping such as planful problem solving, seeking social support, gaining further information and training. However, they tended to be poorer at recognising positive events and emotions and have poorer emotion focused coping or emotion regulation skills. Problem-focused coping is associated with lower levels of burnout in both cross-sectional and longitudinal studies whilst inappropriate, avoidant emotionfocused coping has the opposite association. ${ }^{38}$ Chronic stress results in problems downregulating negative emotions. ${ }^{39} \mathrm{~A}$ study in medical students and physicians $\mathrm{s}^{40}$ found that the ability to self-regulate emotions positively predicted well-being and negatively predicted burnout. These facts strongly suggest that a programme which fosters the recognition of 
positive events and appropriate emotion regulation strategies should reduce stress in dentists. ${ }^{41}$ Burnout is associated with higher rates of self-reported clinical errors. ${ }^{42}$

On the other hand, at least experimentally, it has been found that experiencing positive emotions has a positive effect on decision-making strategy and facilitates creative, flexible and integrated problem-solving. ${ }^{43-45}$ Therefore, encouraging the recognition of positive events in the dental surgery may have a positive effect upon decision-making.

\section{Previous Interventions}

A variety of interventions have been used with healthcare practitioners in order to reduce stress and burnout. ${ }^{46}$ These have included the use of exercise, ${ }^{47}$

Balint/supervision/discussion groups ${ }^{48}$ and mindfulness/meditation training. ${ }^{49} \mathrm{~A}$ recent review of programmes to reduce burnout in physicians ${ }^{50}$ (either individual or organisational interventions) found that stress management programmes (as well as mindfulness-based and small group discussions) were successful in reducing burnout scores, although few studies assessed the long-term effects of the programmes. The authors concluded ${ }^{51}$ that substantive progress in reducing physician (almost exclusively hospital-based) burnout is unlikely to occur until there is a co-ordinated effort to address this issue at the national and state, organization, leader, and individual levels. [E1]

Unfortunately, primary care dental practitioners in the UK practice in a heterogeneous environment (private/ NHS, independent/corporate/salaried services). They run small businesses and yet, if in NHS practice, the fee structure dictates their prices and profitability. Therefore, the only practical proposition for programmes designed for most primary care dentists is to address the individual.

To date, there appear to have been 2 major studies assessing specially designed interventions to tackle dentists' burnout and stress. The first ${ }^{52}$ was an intensive programme of individual counselling and 3 group sessions which lasted 24 hours, included an overnight stay, and ran over 6 months. It was offered to 171 Dutch dentists who had been identified as having unfavourable scores on the Maslach Burnout Inventory (MBI). Forty-five dentists volunteered to participate and, after the initial assessment process, 19 (15 male) chose to participate. There was a control group of 103 (88 male) dentists similarly at risk, but who did not want to participate in the intervention. The control group were subsequently divided into those who, once they knew that burnout was a threat for them, chose to tackle the problem using self-initiative. Seventeen members of the intervention group and 75 members of the control group completed the follow-up measures at 1 month after the final intervention group session. The intervention, at one month, resulted in improvements in MBI burnout scores for emotional exhaustion (EE), personal achievement (PA) and, to a lesser extent, depersonalisation (DP). Dentists who self-initiated an intervention showed improvements in EE and PA, whilst those who did nothing showed no improvement in MBI scores. However, at a further follow-up one year later, the gains of the intervention group seemed to have disappeared, whereas the gains of those who chose self-prevention were maintained. ${ }^{53}$

The second study evaluated a Dental Practitioner Support Service (DPSS) in Kent, UK. ${ }^{54}$ This service included an initial assessment by a counsellor. This was followed by up to 6 hours of consultation with the service's consultants in a personalised, problem-focused programme and covered areas including personal issues such as high expectations of self, low self-esteem, unresolved traumatic experiences; home/work balance; practice issues such as paperwork and patient complaints; interpersonal stress within the practice; concern regarding the ubiquity of stress among NHS dentists. Of the 20 dentists originally recruited to the project, 16 participated in the study and $9(45 \%)$ of these completed a one month follow up. At this point, there was a statistically and clinically meaningful decrease in distress as measured by the General Health Questionnaire. Participants also demonstrated statistically 
significant changes in coping skills (Ways of Coping Questionnaire; confrontation of problems and accepting responsibility for stress reduced). The authors suggested that participants were more accepting that some sources of stress were outside their control. There was no long term follow up.

\section{Bibliotherapy}

'Bibliotherapy' is a standard method of delivering self-help CBT which has been used effectively, particularly in groups with mild symptoms. ${ }^{55-57}$ There are a wide selection of these books available commercially. ${ }^{58,59}$ In these books, engagement with the reader is facilitated by developing a supporting relationship between author and reader; providing psychoeducation and then facilitating the development of CBT-related skills using instruction, exercises and reflection. CBT-based bibliotherapy can also be effectively delivered in an 'assisted' or 'guided' form, in which some therapist input supports the reader as they work through the materials. ${ }^{60,61}$ Mansell ${ }^{62}$ asked users of self-help books for anxiety about the positive properties of such books from the 'consumer's' perspective. Key positive points included; easy to read, author understands with compassion, practical steps provided, includes real vignettes or interviews, and author has been through anxiety. Bibliotherapy can be almost as effective as face-to-face therapy with a counsellor or psychologist ${ }^{63}$ and should therefore be more cost effective than a programme with intensive face-to-face contact. Also, the self-help format allows practitioners to access help without losing clinical time.

\section{Study Aims}

Building on the knowledge gained from previous studies, ${ }^{1,2,19,37}$ this research aimed to evaluate the efficacy of a bespoke CPD package (in both self-help and guided self-help formats) which was designed to improve coping skills and resilience and thereby 1 . reduce participant burnout; 2 . reduce the impact of anxiety on dentists' clinical decision-making and 3. improve decision-making style.

\section{Method}

\section{Participants}

Following ethical approval from the University of Lincoln, School of Psychology Ethics Committee, primary care dentists were recruited via a form enclosed with an earlier epidemiological study..$^{19} \mathrm{~A}$ total of 57 dentists volunteered; 7 were recruited to the pilot study 20 were recruited to the self-help group, receiving the self-help material only; 10 were recruited to a guided self-help package based in Lincoln and 10 in Nottingham. Ten participants were chosen for each guided self-help package as this was considered to be the maximum number with which a group session could successfully be conducted. Two sites were chosen to allow for recruitment across a wider geographical region and to provide potential representation across more and less urban practices as a reflection of the surrounding locale of the two cities. This resulted in 20 participants for the guided self-help package; an additional 20 participants were recruited for the purely self-help group to allow for statistical comparison across mode of delivery of intervention. Participants were allocated by their willingness to participate in the face-to-face workshop session or not, their choice of venue, and then purposefully to ensure that as representative a sample as possible was included in each group. Participants all received an information letter and a further consent form before participating. They received 8 hours CPD for reading a specially written CBT self-help booklet on coping with stress and completing the initial and follow-up questionnaire battery and detailed evaluation questionnaires. Those in the GSH group received an additional 3 hours CPD for attendance at the workshop. 


\section{$\underline{\text { Materials }}$}

Building on previous research, ${ }^{1,2,37}$ as well as the widely established literature (see Gorter ${ }^{64}$ for a review of factors affecting dentists' stress), $\mathrm{HC}$, a dentist with a formal training in CBT and experience in writing CBT self-help material ${ }^{65}$ drafted the self-help CBT package. This aimed to help dentists cope with stress and to understand the process of clinical decisionmaking and how stress affects this. Instead of looking at stressors such as staffing problems, time pressure and business management, this programme was written to tackle stress by building resilience. The 'broaden and build' model was used with an emphasis on noting positive emotions and building coping flexibility ${ }^{31}$ and emotion regulation skills. ${ }^{40}$

Interventions were designed so that they could be used during busy clinical sessions. A number of exercises were included and dentists were encouraged to try them all and to regularly use the ones that they found helpful. The exercises are summarised in Table 1. The booklet was reviewed by RB, a clinical psychologist.

The SH version of the package, psychometric questionnaires and evaluation questionnaire were piloted with a convenience sample of 7 primary care dentists. At six-week follow-up, $\mathrm{HC}$ conducted a semi-structured telephone interview with participants, during which she had sight of their detailed responses in the evaluation questionnaire. All the participants had read the complete booklet; all had shared the contents with colleagues and staff members. They found the language and presentation appropriate, commenting that they "felt understood."

However, two commented on the 'psychobabble', which some nurses found difficult to follow. All requested 'something' on burnout - it was the outcome of stress that they were all familiar with and wanted to acknowledge. However, none of the participants had tried all the practical techniques suggested. Although it had proved difficult at first to identify positive situations, the exercise 'little gems' was universally used, enjoyed and often done in consultation with the nurse. One participant said that she had already transferred the skills to her non-working life and it, "Had changed my life." All believed the amount of CPD offered was realistic for the amount of work involved. The section on burnout, which had previously been omitted to reduce the length of the programme, was reinstated and the text of the booklet was left unchanged as the 'psychobabble' language referred to the explanations of CBT where care had been taken to simplify some of the language, without insulting the reader, as suggested by Williams and Garland. ${ }^{66}$ The programme had a Flesch-Kincaid reading age of grade 9.5 (14-15 years: the equivalent of the BBC News Website) which is the equivalent of the scores of commonly available CBT self-help texts ${ }^{66,67}$ and would have been inflated by the use of technical dental terms within the text and the sentence length in material quoted verbatim from interviews with dentists.

As a result of the interviews, $\mathrm{HC}$ designed the 3-hour workshop for the GSH group that would foster understanding of why the exercises were helpful and encourage participants to try them on at least one occasion; it was reviewed by RB. HC delivered the workshop with $\mathrm{RB}$ observing and assisting with administration.

\section{Procedure}

The SH group received the booklet and questionnaire battery which they were asked to return in a stamped addressed envelope. They were sent up to 2 email reminders and replacement forms as necessary. Two, three-hour long twilight workshops were held in Lincoln and Nottingham as part of the GSH version of the training. Participants completed the initial questionnaire battery before the training and completed an evaluation form of the training. They received 3 hours CPD and refreshments. 
After 6 weeks, all participants were sent a further questionnaire pack and the workbook evaluation questionnaire. Up to 2 email reminders were sent about completing the questionnaires. When they were returned, participants received their certificate for 8 hours CPD (6 General and 2 communications skills).

Six months after the initial evaluation, all SH and GSH participants were asked to complete a further questionnaire battery and evaluation. No further CPD was provided. Up to 3 reminders were sent.

The psychometric data was entered into SPSS (IBM Statistics, Version 22.0, Armonk, NY). The programme evaluation data was entered into, and analysed, using a Microsoft Office 2010 Excel spreadsheet. The open-ended responses were also transferred and grouped thematically by HC.

\section{Questionnaires}

Demographics - This was based on an existing questionnaire ${ }^{68}$ with minor modifications, for example to allow identification for dentists working in the salaried services.

The Maslach Burnout Inventory-Human Services Survey (MBI-HS) ${ }^{9}$ - This is the most commonly used measurement of burnout, which has been widely used with dentists. ${ }^{3,69}$ It has three subscales measuring emotional exhaustion (EE); Depersonalisation (DP); personal achievement (PA), which is reverse scored. Items are scored on a 6 point Likert scale rating how often the feelings are experienced and anchored 'Never; 0 ' to 'Every day; 6.'

Melbourne Decision-Making Questionnaire $(M D M Q)^{70,71}$ - This is a well-validated questionnaire which assesses decision-making style as described by Janis and Mann. It has 2 parts; Part one (6 items) assesses decision-making self-esteem and Part 2 assesses styles of decision-making. There are 4 subscales measuring: vigilance, hypervigilance procrastination and buck-passing. All items are scored on a 3-point scale labelled, true, sometimes true, not true ...for me. Details of the subscales with dental examples are decribed elsewhere. ${ }^{19}$

Dealing with Uncertainty Questionnaire $(D \cup Q)^{72}$ - This was developed to measure the impact of uncertainty on the decision-making process of general medical practitioners. It consists of 2 subscales; 1 . a six item diagnostic action scale and 2. a six item diagnostic reasoning scale It is scored on a six point Likert scale anchored 'strongly agree' and 'strongly disagree.'

Dentists Anxieties in Clinical Situation Scale (DACSS) ${ }^{19}$ - This consists of 20 frequently experienced stressful situations. Dentists are asked to rate their anxiety for each situation on an 11 point Likert scale anchored 0 (not at all) \& 10 (the most intense emotion you can experience). For each item they are asked, 'Does the anxiety ever change something about the way you work?' and are asked to indicate yes or no $(\mathrm{Y} / \mathrm{N})$. The scale therefore has 2 subscales; the DACSS-R which rated anxiety and the DACSS-C which reported change in decision-making. The DACSS-R has 4 subscales: Uncertainties in clinical practice; Threats to sense of control; Challenging patients; Ethical dilemmas

Evaluation questionnaires - Questionnaires to allow participants to evaluate the workshop and the written materials were drafted by $\mathrm{HC}$ and approved by the other authors. A mixture of closed questions, and Likert evaluations were used and an opportunity to comment or expand on the answer was given after each question. The post-workshop evaluation was 
administered at the close of the session. A questionnaire to assess the acceptability/usability of the handbook and use of exercises was enclosed as part of the 6 week follow-up questionnaire battery. The questionnaire which was enclosed with the 6 month follow-up was similar to that at 6 weeks. The text of key questions is presented in Results Tables 5 and 6.

\section{Results}

Details of the sample and retention rates are provided in Tables 2 and 3.

Missing values from questionnaires were replaced with the mean of that subscale for that dentist, with the exclusion of questions R18-R20 from the DACS-R which did not apply to all dentists and therefore were not suitable for missing value replacement. There was no pattern to the missing values. $\mathrm{N}$ for each analysis is shown in Table 4.

Impact of the programme on measures of psychological well-being and decisionmaking

The impact of the programme on subscales of the DASS, MBI, MDMQ, DUQ and DACS was examined by conducting a series of Friedman's ANOVA using calculations of exact significance across time of evaluation (baseline, 6 weeks, 6 months). A significant main effect of time of evaluation was found for DASS(Depression), DASS(Anxiety), DASS(Stress), $\mathrm{MBI}(\mathrm{EE}), \mathrm{MBI}(\mathrm{PA})$ and $\mathrm{MDMQ}$ (Hypervigilance) (Table 4). Post-hoc analyses were conducted on these subscales using Wilcoxon signed ranks to make pairwise comparisons across the three time points. These analyses revealed that DASS(Depression) was significantly reduced at 6 weeks compared to baseline, with the reduction maintained at 6 months compared to baseline. DASS(Anxiety) was significantly reduced at 6 weeks compared to baseline, but the reduction was not maintained at 6 months with anxiety climbing back up to levels similar to baseline values. DASS(Stress) was significantly reduced at 6 weeks compared to baseline, with the reduction maintained at 6 months compared to baseline. $\mathrm{MBI}(\mathrm{EE})$ was significantly reduced at 6 weeks compared to baseline, with the reduction maintained at 6 months compared to baseline. Personal achievement (MBI:PA) was significantly increased at 6 months compared to baseline, but this was not maintained at 6 months. MDMQ (Hypervigilance) was significantly reduced at 6 weeks compared to baseline, with the reduction maintained at 6 months.

\section{Did the mode of delivery make a difference?}

In addition, all outcome variables were examined for differences according to mode of delivery (SH or GSH) using Mann-Whitney pairwise comparisons. With 19 comparisons a Bonferroni corrected $p$ value of 0.003 was taken. There was no significant difference in any outcome variables across mode of delivery (all comparisons $p>.1$ ).

\section{Participants perceptions of the programme}

Key findings from the evaluation of the workshop are summarised in Table 5, showing it was pitched correctly and participants felt comfortable completing the exercises in the group setting.

The key findings of the 6 week and 6 month follow-up questionnaires are summarised in Table 6. The trend is for those in the GSH group to engage more with the materials and to be more aware of and to have made more self-reported metacognitive changes to their decision-making.

At all stages of the evaluation process, participants were given the option of providing qualitative feedback and suggestions. The comments were overwhelmingly positive and could be 'grouped' as follows: 
General comments on the quality/acceptability of the programme:

"Found it easy to read with lots of helpful/practical advice."

"This booklet makes you THINK! It acknowledges (in a very relevant form ie written by a dentist) our stresses."

"Made an awful lot of sense!! Very relevant."

There were reports of

1. generalisation of use of the coping skills taught

"Writing - has helped me with work stress and other personal problems."

2. improved communications skills and

"I try to involve the patients listen more to their opinion."

3. creative use of the skills

"It will be useful to tie in CBT formulation with significant event analysis."

Despite the exercises being designed to take a few minutes to complete, the problems of ongoing commitment within the time pressures of a busy clinical schedule were mentioned by some participants.

"Found setting aside 'worry time' was helpful and making a list of worries, but not sufficient time for 'writing therapy."

Some exercises, such as the almost universally popular 'collecting little gems', were completed collaborative with nurses.

"Discussing the good situations and not just taking them for granted. And when something doesn't go to plan I now also discuss these moments far more with my nurse at the time to see how I/we could avoid the situation reoccurring."

There was evidence of improved insight into clinical decision-making processes; enhanced metacognition.

"I am more aware of how external factors can affect my decision making."

Almost all participants spontaneously commented that they had shared the programme booklet or its contents with colleagues and/or staff members. Eighty percent of participants endorsed the creation of an online version and $83 \%$ endorsed the development of a version for the training for teams. Participants suggested using the programme with other newly qualified dentists and students.

"I have really enjoyed this, I think something similar should be in place for all young dentists."

\section{Discussion}

This project evaluated self-help and guided versions of a CBT bibliotherapy programme addressing stress and the quality of decision-making in dentists. The 2 significant programmes reported to date $\mathrm{e}^{52-54}$ which address stress in dentists appear, from the published details, to have focused on improving (apparently mainly behavioural) coping skills for dealing with stress once it has arisen. They were demanding of time resources including, for example, visits to therapists and weekend stays. They will also have been costly to provide. This difference in approach may explain the lower dropout rates in this intervention (83\% of the SH and $89 \%$ completed the 6 week follow-up and $78 \%$ and $79 \%$, respectively, completed the 6 month follow-up) which is comparable to the intervention with Dutch dentists ${ }^{53}$ and significantly better than the evaluation return rate (45\%) in the British study. ${ }^{54}$ Dropout rates for self-help CBT can be as high as $50 \% .{ }^{73}$ Dropouts increase the perceived effect of any intervention. However, the retention of three quarters of participants may have minimised this.

The programme achieved clinically and statistically significant decreases in depression, anxiety and stress levels among participants as well as a statistical reduction in emotional 
exhaustion and increase in personal achievement. These results are similar to those obtained in Gorter's ${ }^{52}$ initial evaluation of his more intensive programme and his self-help group. Given that the main aim of the project was to foster resilience by, for example, an increased focus on the positive aspects of dental practice, it might be that measures of psychological well-being and resilience would have shown greater levels of improvement. The measure had been omitted for fear of making the evaluation package onerously long. This will be the focus of further research. These gains were largely maintained at 6-month follow-up, unlike the previous studies where a long-term follow-up was either not undertaken, ${ }^{54}$ or the gains made were not maintained. ${ }^{52,53}$ Also, a tendency to relapse at the end of a course of CBT treatment for clinical problems is common and clinical treatment packages taper, include booster sessions and incorporate relapse prevention skills in order to minimise this. ${ }^{74} \mathrm{~A}$ modular delivery with refresher/ extension units might have merit, as the retention of skills and learning would be improved; the spiral curriculum.

Given the nature of the stressors identified in previous research, ${ }^{1,2,37,64}$ it may be that the programme gave an 'initial lift' to participants' well-being, but then the continuing grind of the stressors created by 'the system' eroded the improvements made. A recent meta-analysis of burnout interventions in physicians ${ }^{75}$ found that organisation-directed interventions were more effective than those which focused on the individual. The authors concluded that

burnout is a problem of the whole health care organization, rather than individuals. (epub)

This suggests that unless some of the inherent stressors such as the current remuneration system ${ }^{1,2}$ are modified, programmes designed for individuals are likely to have a reduced effectiveness in the long term.

This has been one of the first studies to evaluate if the unhelpful styles of decision-making (avoidant and hypervigilant) as defined by Janis and Mann, ${ }^{20,70}$ and heuristic decisional style, as defined by Croskerry ${ }^{23,24}$ - can be modified. Practitioners were certainly more metacognitively aware of the use of heuristic decision-making, though this could not be measured objectively. Whether simply slowing down and using analytical-rational thinking improves diagnostic accuracy is controvercial. ${ }^{76}$ The programme objectively reduced hypervigilant decision-making and some dentists commented on being more capable of recognising avoidant decision-making such as buck-passing and taking steps to try and improve the quality of the final decisions taken by using another technique. As hypervigilant decision-making is associated with high levels of anxiety, the decrease might be ascribed to the decrease in stress and anxiety reported, to an increased awareness (because of the training) of the importance of trying not to make decision when in a highly aroused state, or a combination of both factors.

The lack of change in the DUQ scores suggests that dentists may not be fully aware of the impact anxiety is having on their reasoning processes. A previous study ${ }^{37}$ found that dentists would often deny that their emotions, including anxiety, affected their decision-making and then proceeded to describe how it actually changed their clinical approach. The weaker relationship of the DUQ may also reflect a lack of generalisability of the questionnaire from general medical practice. Further research would benefit from the development of a specific measure for dentistry.

The lack of significant decreases in the DACSS scores is disappointing. It might be that dentists still found the situations listed provoked anxiety, still changed how they tackled the problem, but that the coping skills used to deal with the stressors were different. It might even have been that the research raised participants' awareness of changing their clinical procedures as a result of anxiety. Without further detailed research, this is impossible to determine. 
This intervention has several strengths which are relevant to its relative efficacy; it was written by a dentist with a specialist training in CBT, and therefore an empathic therapeutic relationship could be fostered through the text; it focused on building resilience using a menu of skills/activities from which the participants were free to choose the ones used on a regular basis, thereby fostering a sense of control in the participants; the booklet gave a permanent resource which could be drawn upon for reminders at a later date, and thereby offered a distinct advantage over brief face-to-face interventions which may not be so easily recalled.

This programme, by helping dentists cope with day to day stressors, could improve the quality of care as well as decision-making. Choking under pressure - which is associated with disruption of automatic and overlearned processes such as the experienced dentist will use during routine clinical care - has long been established; ${ }^{77}$ reduced stress may reduce clinical errors with implications for improved patient safety.

Levels of perceived stress are subject to natural variability and therefore psychological stress responses are likely to have a natural variation as well. As this evaluation had no notreatment control group, it is theoretical possible that the results observed are due to natural variation. However, the sample size is such and the fact that the 2 groups showed similar improvements mean that this is unlikely. Any further evaluation should include a notreatment control.

This project was deliberately designed to focus on emotion-focused coping (emotion regulation strategies) as dentists had previously reported good problem-solving skills. ${ }^{37}$ It was designed to minimise the impact on surgery time; the booklet could be read at home and in small 'chunks' and the exercises were designed to foster use during busy clinics or in coffee/lunch breaks. It also aimed to prevent stress by building resilience and is thereby appropriate for use by all practitioners as a preventive package rather than a treatment regime, akin to a public health programme.

The feedback at both 6 weeks and 6 months was overwhelmingly positive, in terms of Likerttype evaluation and the open-ended comments. The results suggested that participants engaged more with the material and found it more helpful if they had attended the face-toface workshop (GSH). The writing exercise, in particular, appeared to be more accessible to participants, some of whom commented during the workshop that they were sceptical about the exercise, but much to their surprise, found it helpful.

The workshop helped participants engage with the decision-making material and to consciously change the nature of their decision-making; these subjective results are consistent with the objective reduction in hypervigilant decision-making as measured by the changes in the MDMQ scores.

At the individual level, participants obviously found some exercises very useful and others not at all, justifying the design which suggested participants try all the exercises and continued to use only those that they found helpful.

The qualitative feedback suggested that the project met 'consumer' requirements as described by Mansell. ${ }^{62}$ Despite the lack of statistically significant differences between the $\mathrm{SH}$ and GSH groups in the improvements in the psychometric measures, there was a trend towards better engagement with the materials in the GSH format. The few trials that have compared SH with GSH (usually using internet delivery), have found similar trends. ${ }^{78,79}$ However, it might be that a larger sample would reveal a significant difference in response, particularly with longer term continuing use of the coping skills learned. 
Any further evaluation of the project should include exit interviews or focus group to evaluate the project.

The dentists were enthusiastic about expanding the programme such as the development of an internet-delivered package and a programme for the whole of the dental team. However, the nature of the stressors is different for students ${ }^{80}$ and the programme could not be ethically used with them without further research and modification to meet their specific needs.

In conclusion, this training package has proved to be effective at helping dentists reduce their psychological distress in the short and longer terms and has improved their decisionmaking style and metacognition, with implications for improved patient safety and outcomes. It is worthy of further development. 


\section{$\underline{\text { References }}$}

1. Bretherton, R., Chapman, H.R. \& Chipchase, S. A study to explore specific stressors and coping strategies in primary dental care practice. Br Dent J 220, 471-478 (2016).

2. Chapman, H.R., Chipchase, S.Y. \& Bretherton, R. Understanding emotionally relevant situations in primary care dental practice: 1 . Clinical situations and emotional responses. Br Dent J 219, 401-409 (2015).

3. Denton, D.A., Newton, J.T. \& Bower, E.J. Occupational burnout and work engagement: a national survey of dentists in the United Kingdom. Br. Dent J 205, E13-E13 (2008).

4. Johns, R.E. \& Jepsen, D.M. Sources of occupational stress in NSW and ACT dentists. Aust. Dent J (2015).

5. Ayers, K.M., Thomson, W.M., Newton, J.T. \& Rich, A.M. Job stressors of New Zealand dentists and their coping strategies. Occup. Med (Lond) 58, 275-281 (2008).

6. Jin, M.U., Jeong, S.H., Kim, E.K., Choi, Y.H. \& Song, K.B. Burnout and its related factors in Korean dentists. Int Dent $J$ (2014).

7. te Brake, H., Smits, N., Wicherts, J.M., Gorter, R.C. \& Hoogstraten, J. Burnout development among dentists: a longitudinal study. Eur. J Oral Sci 116, 545-551 (2008).

8. Maslach, C., Schaufeli, W.B. \& Leiter, M.P. Job Burnout. Annual Review of Psychology 52, 397-422 (2001).

9. Maslach, C., Jackson, S., E. \& Leiter, M. Maslach Burnout Inventory Manual, (Mind Garden Inc, Menlo Park, California, 1986).

10. Leiter, M.P. \& Maslach, C. Six areas of worklife: a model of the organizational context of burnout. Journal Of Health And Human Services Administration 21, 472-489 (1999).

11. DiMatteo, M.R., Shugars, D.A. \& Hays, R.D. Occupational stress, life stress and mental health among dentists. Journal of Occupational and Organizational Psychology 66, 153-162 (1993).

12. Gorter, R.C., Eijkman, M.A. \& Hoogstraten, J. Burnout and health among Dutch dentists. Eur. J Oral Sci 108, 261-267 (2000).

13. Deligkaris, P., Panagopoulou, E., Montgomery, A.J. \& Masoura, E. Job burnout and cognitive functioning: A systematic review. Work \& Stress 28, 107-123 (2014).

14. Shanafelt, T.D., et al. Burnout and medical errors among American surgeons. Ann Surg 251, 995-1000 (2010).

15. West, C.P., et al. Association of Perceived Medical Errors With Resident Distress and Empathy. JAMA: The Journal of the American Medical Association 296, 10711078 (2006).

16. Balch, C.M., Freischlag, J.A. \& Shanafelt, T.D. Stress and burnout among surgeons: understanding and managing the syndrome and avoiding the adverse consequences. Arch Surg 144, 371-376 (2009).

17. Osterberg, K., Skogsliden, S. \& Karlson, B. Neuropsychological sequelae of workstress-related exhaustion. Stress 17, 59-69 (2014).

18. Arora, S., et al. The impact of stress on surgical performance: a systematic review of the literature. Surgery 147, 318-330, 330 (2010).

19. Chipchase, S.Y., Chapman, H.R. \& Bretherton, R. A study to explore if dentists' anxiety affects their clinical decision-making. Br Dent $\mathbf{J}$ 222, 277-290 (2017).

20. Janis, I.L. \& Mann, L. Decision Making: a psychological analysis of conflict, choice, and commitment., (The Free Press, New York, 1977).

21. Croskerry, P., Abbass, A.A. \& Wu, A.W. How doctors feel: Affective issues in patients' safety. The Lancet 372, 1205-1206 (2008).

22. Norman, G.R. \& Eva, K.W. Diagnostic error and clinical reasoning. Medical Education 44, 94-100 (2010). 
23. Croskerry, P. Clinical cognition and diagnostic error: Applications of a dual process model of reasoning. Advances in Health Sciences Education 14, 27-35 (2009).

24. Croskerry, P. A universal model of diagnostic reasoning. Academic Medicine 84, 1022-1028 (2009).

25. Tversky, A. \& Kahneman, D. Judgment under uncertainty: Heuristics and biases. Science 185, 1124-1131 (1974).

26. Sherbino, J., Dore, K.L., Siu, E. \& Norman, G.R. The effectiveness of cognitive forcing strategies to decrease diagnostic error: An exploratory study. Teaching and Learning in Medicine 23, 78-84 (2011).

27. Sherbino, J., Kulasegaram, K., Howey, E. \& Norman, G. Ineffectiveness of cognitive forcing strategies to reduce biases in diagnostic reasoning: a controlled trial. CJEM 16, 34-40 (2014).

28. Graber, M.L., et al. Cognitive interventions to reduce diagnostic error: a narrative review. BMJ Quality \& Safety 21, 535-557 (2012).

29. Rutter, M. Resilience in the face of adversity. Protective factors and resistance to psychiatric disorder. The British Journal Of Psychiatry: The Journal Of Mental Science 147, 598-611 (1985).

30. Hjemdal, O., Friborg, O., Stiles, T.C., Rosenvinge, J.H. \& Martinussen, M. Resilience Predicting Psychiatric Symptoms: A Prospective Study of Protective Factors and their Role in Adjustment to Stressful Life Events. Clinical Psychology \& Psychotherapy 13, 194-201 (2006).

31. Friborg, O., Hjemdal, O., Rosenvinge, J.H. \& Martinussen, M. A new rating scale for adult resilience: What are the central protective resources behind healthy adjustment? International Journal of Methods in Psychiatric Research 12, 65-76 (2003).

32. Wagnild, G.M. \& Young, H.M. Development and psychometric evaluation of the Resilience Scale. Journal of Nursing Measurement 1, 165-178 (1993).

33. Aiena, B.J., Baczwaski, B.J., Schulenberg, S.E. \& Buchanan, E.M. Measuring resilience with the RS-14: a tale of two samples. Journal of Personality Assessment 97, 291-300 (2015).

34. Fredrickson, B.L., Tugade, M.M., Waugh, C.E. \& Larkin, G.R. What good are positive emotions in crises? A prospective study of resilience and emotions following the terrorist attacks on the United States on September 11th, 2001. J Pers Soc Psychol 84, 365-376 (2003).

35. Fredrickson, B.L. What good are positive emotions? Review of General Psychology 2, 300-319 (1998).

36. Tugade, M.M. \& Fredrickson, B.L. Resilient individuals use positive emotions to bounce back from negative emotional experiences. J Pers Soc Psychol 86, 320-333 (2004).

37. Chapman, H.R., Chipchase, S.Y. \& Bretherton, R. Understanding emotionally relevant situations in primary dental practice. 2. Reported effects of emotionally charged situations. Br Dent J 219, E8 (2015).

38. Carmona, C., Buunk, A.P., Peiro, J.M., Rodriguez, I. \& Bravo, M.J. Do social comparison and coping styles play a role in the development of burnout? Crosssectional and longitudinal findings. Journal of Occupational and Organizational Psychology 79, 85-99 (2006).

39. Golkar, A., et al. The influence of work-related chronic stress on the regulation of emotion and on functional connectivity in the brain. PLOS ONE 9, e104550 (2014).

40. Gagnon, M.-C.J., Durand-Bush, N. \& Young, B.W. Self-regulation capacity is linked to wellbeing and burnout in physicians and medical students: Implications for nurturing self-help skills. International Journal of Wellbeing 6, 101-116 (2016).

41. Bono, J.E., Glomb, T.M., Shen, W.I.N.N., Kim, E.U.G.E. \& Koch, A.J. Buiding positive resources: effects of positive events and positive reflection on work stress and health. Academy of Management Journal 56, 1601-1627 (2013). 
42. Prins, J.T., et al. Burnout, engagement and resident physicians' self-reported errors. Psychology, Health \& Medicine 14, 654-666 (2009).

43. Isen, A.M., Daubman, K.A. \& Nowicki, G.P. Positive affect facilitates creative problem solving. Journal of Personality and Social Psychology 52, 1122-1131 (1987).

44. Isen, A.M. \& Means, B. The influence of positive affect on decision-making strategy. Social Cognition 2, 18-31 (1983).

45. Isen, A.M., Rosenzweig, A.S. \& Young, M.J. The influence of positive affect on clinical problem solving. Med Decis Making 11, $221-227$ (1991).

46. Asuero, A.M., et al. Effectiveness of a mindfulness education program in primary health care professionals: a pragmatic controlled trial. J Contin. Educ. Health Prof $\mathbf{3 4 ,}$ 4-12 (2014).

47. Brennan, J. \& McGrady, A. Designing and implementing a resiliency program for family medicine residents. Int J Psychiatry Med (2015).

48. Nielsen, H.G. \& Tulinius, C. Preventing burnout among general practitioners: is there a possible route? Educ Prim Care 20, 353-359 (2009).

49. Shapiro, S.L., Astin, J.A., Bishop, S.R. \& Cordova, M. Mindfulness-Based Stress Reduction for Health Care Professionals: Results From a Randomized Trial. International Journal of Stress Management 12, 164-176 (2005).

50. West, C.P., Dyrbye, L.N., Erwin, P.J. \& Shanafelt, T.D. Interventions to prevent and reduce physician burnout: a systematic review and meta-analysis. Lancet (2016).

51. Shanafelt, T.D., Dyrbye, L.N. \& West, C.P. Addressing Physician Burnout: The Way Forward. Jama (2017).

52. Gorter, R.C., Eijkman, M.A. \& Hoogstraten, J. A career counseling program for dentists: effects on burnout. Patient Educ Couns 43, 23-30 (2001).

53. te Brake, H., Gorter, R., Hoogstraten, J. \& Eijkman, M. Burnout intervention among Dutch dentists: long-term effects. Eur. J Oral Sci 109, 380-387 (2001).

54. Newton, J.T., Allen, C.D., Coates, J., Turner, A. \& Prior, J. How to reduce the stress of general dental practice: the need for research into the effectiveness of multifaceted interventions. Br. Dent J 200, 437-440 (2006).

55. Moldovan, R., Cobeanu, O. \& David, D. Cognitive bibliotherapy for mild depressive symptomatology: Randomized clinical trial of efficacy and mechanisms of change. Clinical Psychology \& Psychotherapy 20, $482-493$ (2013).

56. Sharma, V., et al. Bibliotherapy to decrease stress and anxiety and increase resilience and mindfulness: a pilot trial. Explore (New York, N.Y.) 10, 248-252 (2014).

57. White, J. Stresspac: A controlled trial of a self-help package for the anxiety disorders. Behavioural and Cognitive Psychotherapy 23, 89-107 (1995).

58. Davies, W. Overcoming anger and irritability: A self-help guide using cognitive behavioral techniques, (Robinson, London, 2000).

59. Kennerley, H. Overcoming Anxiety - A self-help guide using Cognitive Behavioural Techniques, (Robinson, London, 2014).

60. Kupshik, G.A. \& Fisher, C.R. Assisted bibliotherapy: effective, efficient treatment for moderate anxiety problems. Br J Gen Pract 49, 47-48 (1999).

61. Reeves, T. A controlled study of assisted bibliotherapy: an assisted self-help treatment for mild to moderate stress and anxiety. Journal Of Psychiatric And Mental Health Nursing 17, 184-190 (2010).

62. Mansell, W. Reading about self-help books on cognitive-behavioural therapy for anxiety disorders. Psychiatric Bulletin 31, 238-240 (2007).

63. Haug, T., Nordgreen, T., Öst, L.G. \& Havik, O.E. Self-help treatment of anxiety disorders: A meta-analysis and meta-regression of effects and potential moderators. Clinical Psychology Review 32, 425-445 (2012).

64. Gorter, R.C., Albrecht, G., Hoogstraten, J. \& Eijkman, M.A. Measuring work stress among Dutch dentists. Int Dent J 49, 144-152 (1999).

65. Chapman, H.R. \& Kirby-Turner, N. Getting through Dental Fear with CBT: A young person's guide, (Blue Stallion Publications, Witney, UK, 2006). 
66. Williams, C. \& Garland, A. A cognitive-behavioural therapy assessment model for use in everyday clinical practice. Advances in Psychiatric Treatment 8, 172-179 (2002).

67. Richardson, R., Richards, D.A. \& Barkham, M. Self-help books for people with depression: A scoping review. Journal of Mental Health 17, 543-552 (2008).

68. Gilmour, J., Stewardson, D.A., Shugars, D.A. \& Burke, F.J. An assessment of career satisfaction among a group of general dental practitioners in Staffordshire. Br. Dent $J$ 198, 701-704, discussion (2005).

69. Osborne, D. \& Croucher, R. Levels of burnout in general dental practitioners in the south-east of England. Br. Dent. J 177, 372-377 (1994).

70. Mann, L., Burnett, P., Radford, M. \& Ford, S. The Melbourne Decision Making Questionnaire: An Instrument for Measuring Patterns for Coping with Decisional Conflict. Journal of Behavioral Decision Making 10, 1-19 (1997).

71. Mann, L., et al. Cross-cultural Differences in Self-reported Decision-making Style and Confidence. International Journal of Psychology 33, 325-335 (1998).

72. Schneider, A., et al. How do primary care doctors deal with uncertainty in making diagnostic decisions? The development of the 'Dealing with Uncertainty Questionnaire' (DUQ). J. Eval. Clin. Pract 16, 431-437 (2010).

73. Williams, C. New technologies in self-help: Another effective way to get better? European Eating Disorders Review 11, 170-182 (2003).

74. Antony, M.M., Ledley, D.R. \& Heimberg, R.G. Improving outcomes and preventing relapse in cognitive-behavorial therapy, (Guilford Press, New York, NY, US, 2005).

75. Panagioti, M., et al. Controlled Interventions to Reduce Burnout in Physicians: A Systematic Review and Meta-analysis. JAMA Intern Med (2016).

76. Norman, G., et al. The etiology of diagnostic errors: a controlled trial of system 1 versus system 2 reasoning. Academic Medicine: Journal Of The Association Of American Medical Colleges 89, 277-284 (2014).

77. Baumeister, R.F. Choking under pressure: Self-consciousness and paradoxical effects of incentives on skillful performance. Journal of Personality and Social Psychology 46, 610-620 (1984).

78. Furmark, T., et al. Guided and unguided self-help for social anxiety disorder: Randomised controlled trial. The British Journal of Psychiatry 195, 440-447 (2009).

79. Berger, T., Hämmerli, K., Gubser, N., Andersson, G. \& Caspar, F. Internet-based treatment of depression: A randomized controlled trial comparing guided with unguided self-help. Cognitive Behaviour Therapy 40, 251-266 (2011).

80. Harris, M., Wilson, J.C., Holmes, S. \& Radford, D.R. Perceived stress and well-being among dental hygiene and dental therapy students. Br Dent J 222, 101-106 (2017).

81. Chapman, H.R. Chipchase, S.Y. \& Bretherton, R. Understanding emotionally relevant situations in primary dental practice. 3. Emerging narratives $\mathrm{Br}$ Dent J 219, 491-496 2015.

82. Johna, S., et al. (2014). "What can we learn from narratives in medical education?" Perm. J 18(2): 92-94.

83. Pennebaker, J. W. (1990). Opening Up - the Healing Power of Expressing Emotions. New York, Guilford Press.

84. Pennebaker, J. W. (2014). Expressive Writing: Words that Heal, Idyll Arbor.

85. Kolb, D. A. (2014). Experiential Learning - Experience as the source of learning and development. Upper Sadle River, New Jersey, Pearson FT Press.

86. Borkovec, T. D., et al. (1983). "Stimulus control applications to the treatment of worry." Behaviour Research and Therapy 21(3): 247-251.

87. Satterfield, J. M. (2012) Coping with Stress: Cognitive -Behavioral Stress Reduction California, USA, University of California Television. www.youtube.com/watch?v=0BbHW3H_xmo Accessed 03/12/2013 
88. Greenberger, D. and C. A. Padesky (1995). Mind Over Mood. New York, The Guilford Press.

89. Martin, R. C. and E. R. Dahlen (2005). "Cognitive emotion regulation in the prediction of depression, anxiety, stress, and anger." Personality and Individual Differences 39(7): 1249-1260.

90. Esch, T. (2014). The neurobiology of meditation and mindfulness. Meditation Neuroscientific approaches and philosophical implications. S. Schmidt, H. Walach, S. Schmidt and H. Walach. Cham, Switzerland, Springer International Publishing. 2: 153-173.

91. Manzoni, G. M., et al. (2008). "Relaxation training for anxiety: a ten-years systematic review with meta-analysis." BMC Psychiatry 8: 41-41. 



\section{Resubmitted MSS-2016-856 tables}

\begin{tabular}{|c|c|c|}
\hline Exercise & Description & Purpose \\
\hline Collecting little gems & $\begin{array}{l}\text { Noting the small positive experiences which } \\
\text { dentists often overlook }\end{array}$ & To build resilience (broaden and build) ${ }^{35,41}$ \\
\hline $\begin{array}{l}\text { Reflecting on coping - both positive and } \\
\text { negative }\end{array}$ & $\begin{array}{l}\text { Reflecting on what went well. } \\
\text { Reflecting on what went badly or, } \\
\text { preferable, } \\
\text { "What I could have done differently/better." } \\
\text { Encouraged to tie into a CBT formulation to } \\
\text { structure the problem } 81\end{array}$ & $\begin{array}{l}\text { To build resilience (broaden and build) } \\
\text { Reflective practice } \\
\text { To learn from experience } \\
\text { To }\end{array}$ \\
\hline Asking the patients & $\begin{array}{l}\text { At end of session asking patients about } \\
\text { positive and negative aspects of their } \\
\text { experience. }\end{array}$ & $\begin{array}{l}\text { Aimed at } \\
\text { 1. diffusing patient disgruntlement } \\
\text { 2. building rapport }\end{array}$ \\
\hline $\begin{array}{l}\text { Expressing emotions safely. } \\
\text { 1. Writing therapy } \\
\text { 2. Worry time } \\
\text { 3. Mood management exercise }\end{array}$ & $\begin{array}{l}\text { 1. Writing about experiences. }{ }^{82-84} \\
\text { 2. Setting } 5 \text { minutes aside at the end } \\
\text { of session/work/end of the day to } \\
\text { worry. }^{86} \\
\text { 3. As described by Satterfield }{ }^{87}\end{array}$ & $\begin{array}{l}\text { 1. Emotion regulation } \\
\text { 2. Reduce frequency of worry episodes } \\
\text { 3. Reduction of burnout }\end{array}$ \\
\hline Constructing a CBT model or formulation & Constructing a diagram of events ${ }^{88}$ & To facilitate understanding of situation \\
\hline Disputing unhelpful cognitions & Reappraisal of unhelpful negative thoughts & Emotion regulation $^{89}$ \\
\hline Relaxation/meditation & $\begin{array}{l}\text { Readily obtainable resources } \\
\text { recommended }\end{array}$ & To modulate physiological stress response ${ }^{90,91}$ \\
\hline
\end{tabular}




\begin{tabular}{|c|c|c|c|}
\hline \multicolumn{4}{|l|}{ Table 2 Demographics } \\
\hline & $\begin{array}{l}\text { Self-help } \\
\text { CBT }\end{array}$ & $\begin{array}{l}\text { Guided Self- } \\
\text { help CBT }\end{array}$ \\
\hline \multicolumn{2}{|l|}{ Number of Participants } & 18 & 17 \\
\hline \multirow[t]{2}{*}{ Gender } & Male & 6 & 6 \\
\hline & Female & 12 & 11 \\
\hline \multirow[t]{3}{*}{ Type of practice } & GDS & 15 & 15 \\
\hline & CDS & 2 & 0 \\
\hline & Armed Forces & 1 & 2 \\
\hline \multirow[t]{3}{*}{ Type of GDS Practice } & $<75 \%$ NHS & 8 & 9 \\
\hline & $>75 \% \mathrm{NHS}$ & 5 & 5 \\
\hline & 50-50 Mixed & 2 & 1 \\
\hline \multirow[t]{4}{*}{ Location } & City/town centre & 11 & 10 \\
\hline & Suburban & 5 & 6 \\
\hline & Rural & 1 & 1 \\
\hline & All of the above & 0 & 1 \\
\hline \multirow[t]{2}{*}{ GDS practice size } & Single handed & 1 & 3 \\
\hline & Group & 14 & 11 \\
\hline \multirow[t]{4}{*}{ Job Role } & Principal & 3 & 4 \\
\hline & Associate & 7 & 10 \\
\hline & DF1 & 5 & 1 \\
\hline & Salaried & 3 & 2 \\
\hline Special Clinical interest & & 4 & 6 \\
\hline \multirow[t]{5}{*}{ Hours worked } & $<25$ hours & 4 & 6 \\
\hline & $25-35$ & 7 & 8 \\
\hline & $36-45$ & 5 & 3 \\
\hline & $46+$ & 1 & 0 \\
\hline & Missing & 1 & 0 \\
\hline \multirow[t]{4}{*}{ Place of qualification } & UK & 15 & 13 \\
\hline & EU & 2 & 1 \\
\hline & Rest of World & 1 & 1 \\
\hline & Missing & & 2 \\
\hline \multirow[t]{2}{*}{ Date of Qualification } & & $1975-2012$ & $1976-2012$ \\
\hline & Mean & $\begin{array}{l}1990.88 \\
\text { (SD 10.23) }\end{array}$ & $\begin{array}{l}1998.71 \\
\text { (SD 12.61) }\end{array}$ \\
\hline \multirow[t]{2}{*}{ Years in primary dental practice } & Range & $1-38$ & $1-37$ \\
\hline & Mean & $\begin{array}{l}13.44 \\
\text { (SD 12.09) }\end{array}$ & $\begin{array}{l}20.82 \\
\text { SD 11.06) }\end{array}$ \\
\hline
\end{tabular}




\begin{tabular}{|l|l|l|}
\hline \multicolumn{2}{|l|}{ Table 3 Details of Sample Retention } & Guided Self-Help (N) \\
\hline & Self-Help (N) & $\begin{array}{l}20 \\
(10 \text { Lincoln; 10 Nottingham) }\end{array}$ \\
\hline Recruited & 20 & 19 \\
& & $(10$ Lincoln; 9 Nottingham) \\
\hline Consented to participate & 18 & 17 \\
\hline Completed six week follow up & 15 & 15 \\
\hline Completed six month follow up & 14 & \\
\hline
\end{tabular}


Table 4 Analysis of outcome variable changes from baseline to 6 week evaluation and 6 month evaluation

\begin{tabular}{|c|c|c|c|c|c|c|c|}
\hline Outcome variable & $\begin{array}{l}\text { Time } 1 \\
\text { Mean } \\
\text { (S.D.) }\end{array}$ & $\begin{array}{l}\text { Time } 2 \\
\text { Mean } \\
\text { (S.D.) }\end{array}$ & $\begin{array}{l}\text { Time } 3 \\
\text { Mean } \\
\text { (S.D.) }\end{array}$ & $\begin{array}{l}\text { Results of } \\
\text { Friedman's ANOVA, } \\
\text { using exact } \\
\text { significance (across } \\
\text { time) }\end{array}$ & $\begin{array}{l}\text { Pairwise comparison } \\
\text { (Wilcoxon) } \\
\text { Time } 1-2 \text { (1-tailed) } \\
(\mathrm{N}=32)\end{array}$ & $\begin{array}{l}\text { Pairwise comparison } \\
\text { (Wilcoxon) } \\
\text { Time 2-3 (1-tailed) } \\
(\mathrm{N}=28)\end{array}$ & $\begin{array}{l}\text { Pairwise comparisons } \\
\text { (Wilcoxon) } \\
\text { Time } 1-3 \text { (1-tailed) } \\
(\mathrm{N}=29)\end{array}$ \\
\hline $\begin{array}{l}\text { DASS (Depression) } \\
(\mathrm{N}=28)\end{array}$ & $\begin{array}{l}9.93 \\
(6.43)\end{array}$ & $6.29(7.50)$ & $7.44(8.15)$ & $\begin{array}{l}X^{2}(2)=12.46 \\
p<.001\end{array}$ & $\begin{array}{l}z=-3.10 \\
p=.001\end{array}$ & $\begin{array}{l}z=-0.72 \\
p=.244\end{array}$ & $\begin{array}{l}z=-2.37 \\
p=.008\end{array}$ \\
\hline DASS (Anxiety) $(\mathrm{N}=28)$ & $7.57(6.78)$ & $5.43(7.26)$ & $6.71(7.57)$ & $\begin{array}{l}\mathrm{X}^{2}(2)=6.17 \\
p=.045\end{array}$ & $\begin{array}{l}z=-2.86 \\
p=.001\end{array}$ & $\begin{array}{l}z=-1.26 \\
p=.108\end{array}$ & $\begin{array}{l}z=-0.78 \\
p=.220\end{array}$ \\
\hline DASS (Stress) $(\mathrm{N}=28)$ & $\begin{array}{l}17.93 \\
(9.16)\end{array}$ & $\begin{array}{l}12.86 \\
(7.10)\end{array}$ & $\begin{array}{l}13.29 \\
(9.60)\end{array}$ & $\begin{array}{l}X^{2}(2)=10.12 \\
p=.005\end{array}$ & $\begin{array}{l}z=-2.93 \\
p=.001\end{array}$ & $\begin{array}{l}z=-3.05 \\
p=.385\end{array}$ & $\begin{array}{l}z=-2.55 \\
p=.005\end{array}$ \\
\hline $\begin{array}{l}\text { MBI (Depersonalisation) } \\
(\mathrm{N}=28)\end{array}$ & $1.36(0.97)$ & $1.38(0.84)$ & $1.63(1.36)$ & $\begin{array}{l}X^{2}(2)=3.37 \\
p=.186\end{array}$ & & & \\
\hline $\begin{array}{l}\mathrm{MBI}(\text { Emotional } \\
\text { Exhaustion) }(\mathrm{N}=28)\end{array}$ & $3.03(1.47)$ & $2.67(1.14)$ & $2.66(1.47)$ & $\begin{array}{l}\mathrm{X}^{2}(2)=6.22 \\
p=.044\end{array}$ & $\begin{array}{l}z=-2.26 \\
p=.011\end{array}$ & $\begin{array}{l}z=-0.09 \\
p=.468\end{array}$ & $\begin{array}{l}z=-1.80 \\
p=.036\end{array}$ \\
\hline $\begin{array}{l}\mathrm{MBI} \text { (Personal } \\
\text { Achievement) }(\mathrm{N}=28)\end{array}$ & $0.68(0.48)$ & $0.50(0.50)$ & $0.57(0.52)$ & $\begin{array}{l}X^{2}(2)=7.00 \\
p=.029\end{array}$ & $\begin{array}{l}Z=-2.18 \\
p=.014\end{array}$ & $\begin{array}{l}z=-0.89 \\
p=.191\end{array}$ & $\begin{array}{l}z=-1.42 \\
p=.080\end{array}$ \\
\hline $\begin{array}{l}\text { MDMQ (Vigilance) } \\
(\mathrm{N}=28)\end{array}$ & $1.71(0.31)$ & $1.77(0.29)$ & $1.71(0.26)$ & $\begin{array}{l}\mathrm{X}^{2}(2)=1.38 \\
p=.525\end{array}$ & & & \\
\hline $\begin{array}{l}\text { MDMQ (Buckpassing) } \\
(\mathrm{N}=28)\end{array}$ & $0.80(0.51)$ & $0.78(0.42)$ & $0.86(0.46)$ & $\begin{array}{l}X^{2}(2)=2.25 \\
p=.348\end{array}$ & & & \\
\hline $\begin{array}{l}\text { MDMQ (Procrastination) } \\
(\mathrm{N}=28)\end{array}$ & $0.53(0.44)$ & $0.46(0.36)$ & $0.48(0.38)$ & $\begin{array}{l}\mathrm{X}^{2}(2)=0.46 \\
p=.818\end{array}$ & & & \\
\hline $\begin{array}{l}\text { MDMQ (Hypervigilance) } \\
(\mathrm{N}=28)\end{array}$ & $1.10(0.42)$ & $0.96(0.49)$ & $0.94(0.46)$ & $\begin{array}{l}\mathrm{X}^{2}(2)=8.57 \\
p=.013\end{array}$ & $\begin{array}{l}z=-1.95 \\
p=.026\end{array}$ & $z=-0.11, p=.462$ & $\begin{array}{l}z=-1.88 \\
p=.029\end{array}$ \\
\hline $\begin{array}{l}\text { MDMQ (Decision Self- } \\
\text { Esteem) }(\mathrm{N}=28)\end{array}$ & $8.54(2.49)$ & $8.89(2.22)$ & $8.96(2.38)$ & $\begin{array}{l}\mathrm{X}^{2}(2)=2.40 \\
p=.308\end{array}$ & & & \\
\hline $\begin{array}{l}\text { DUQ (Diagnostic Action) } \\
(\mathrm{N}=28)\end{array}$ & $\begin{array}{l}26.75 \\
(5.34)\end{array}$ & $\begin{array}{l}26.57 \\
(5.88)\end{array}$ & $\begin{array}{l}26.79 \\
(6.53)\end{array}$ & $\begin{array}{l}X^{2}(2)=0.18 \\
p=.922\end{array}$ & & & \\
\hline $\begin{array}{l}\text { DUQ (Diagnostic } \\
\text { Reasoning) }(\mathrm{N}=28)\end{array}$ & $\begin{array}{l}18.10 \\
(3.72)\end{array}$ & $\begin{array}{l}18.39 \\
(3.12)\end{array}$ & $\begin{array}{l}18.11 \\
(3.75)\end{array}$ & $\begin{array}{l}\mathrm{X}^{2}(2)=0.06 \\
p=.982\end{array}$ & & & \\
\hline
\end{tabular}




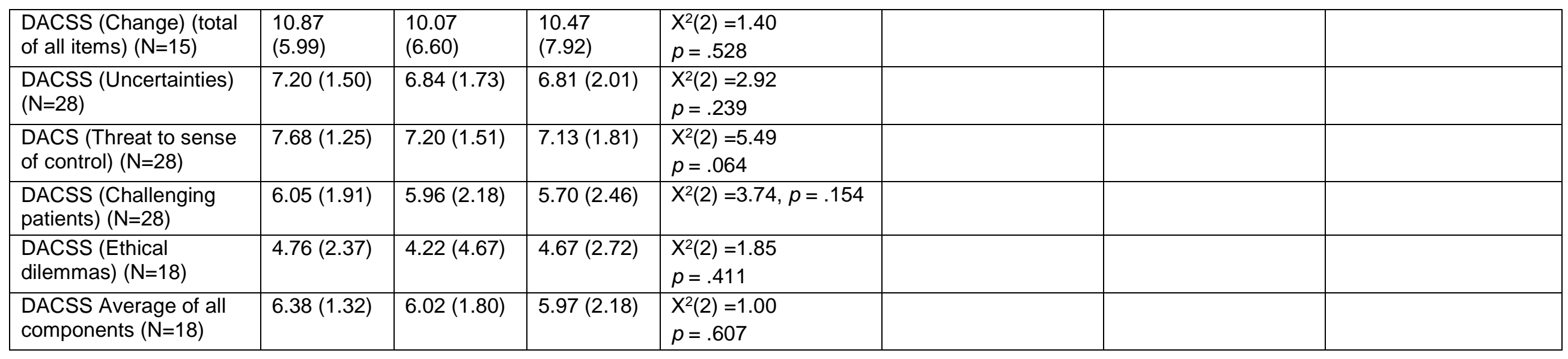




\begin{tabular}{|c|c|}
\hline Question asked & \% - Response \\
\hline $\begin{array}{l}\text { Was the format of the workshop } \\
\text { Likert Scale: } 1 \text { not challenging enough / } \\
3 \text { just right / } 5 \text { too challenging? }\end{array}$ & \begin{tabular}{|l|}
$84 \%-3$ \\
$16 \%-4$
\end{tabular} \\
\hline $\begin{array}{l}\text { Did you feel comfortable doing these } \\
\text { exercises in this setting? } \\
\text { Likert Scale: } 1=\text { not at all --- } 5 \text { = completely }\end{array}$ & \begin{tabular}{|l|}
$26.3 \%-4$ \\
$63.5 \%-5$
\end{tabular} \\
\hline $\begin{array}{l}\text { As a result of having done the workshop, } \\
\text { do you think you are } \\
\text { More likely / Less likely / Not sure? } \\
\text { to do these exercises once you are back in } \\
\text { your surgery? }\end{array}$ & $\begin{array}{l}95 \% \text { More likely } \\
5 \% \text { Less likely } \\
\text { (But specified } \\
\text { relaxation exercise.) }\end{array}$ \\
\hline
\end{tabular}




\begin{tabular}{|c|c|c|c|c|c|c|}
\hline & \multicolumn{2}{|c|}{6 Week follow-up } & \multicolumn{4}{|c|}{6 Month follow-up } \\
\hline & $\begin{array}{l}\text { Self-help } \\
N=15\end{array}$ & \begin{tabular}{|l|} 
Guided \\
Self-help \\
$\mathrm{N}=17$
\end{tabular} & \multicolumn{2}{|l|}{$\begin{array}{l}\text { Self-help } \\
N=14\end{array}$} & \multicolumn{2}{|c|}{$\begin{array}{l}\text { Guided Self-help } \\
N=15\end{array}$} \\
\hline \multicolumn{7}{|c|}{$\begin{array}{l}\text { Participants who reported using resilience building/coping exercises at } 6 \text { week and } 6 \text { month follow-up } \\
\text { and, at } 6 \text { month only, how useful they found the exercises on a Rating Scale of } 1-10\end{array}$} \\
\hline Exercise & Use (\%) & Use (\%) & Use (\%) & $\begin{array}{l}\text { Usefulness } \\
\text { Mean (SD) }\end{array}$ & Use (\%) & $\begin{array}{l}\text { Usefulness } \\
\text { Mean (SD) }\end{array}$ \\
\hline $\begin{array}{l}\text { Reflecting on the positives } \\
\text { (collecting little gems) }\end{array}$ & $14(93)$ & $17(100)$ & $13(93)$ & $7.00(2.16)$ & $13(87)$ & $8.07(1.85)$ \\
\hline Asking the patients & $9(60)$ & $6(35)$ & $7(50)$ & $7.29(1.89)$ & $8(53)$ & $5.88(3.00)$ \\
\hline Reflecting on your coping & --- & $\mid---$ & $8(57)$ & $4.75(3.06)$ & $11(73)$ & $6.83(1.85)$ \\
\hline Expressing emotions safely & $8(53)$ & $14(82)$ & 0 & 0 & $9(60)$ & $6.78(4.05)$ \\
\hline Mood management exercise & --- & \begin{tabular}{|c|}
--- \\
\end{tabular} & $3(21)$ & $2.75(2.5)$ & $4(36)$ & $6(2.82)$ \\
\hline Worry Time & --- & $\mid---$ & $2(14)$ & $6.50(0.71)$ & $7(47)$ & $6.23(1.98)$ \\
\hline $\begin{array}{l}\text { Draw CBT formulation of event } \\
\text { to aid understanding }\end{array}$ & --- & \begin{tabular}{|l|}
---- \\
\end{tabular} & $1(7)$ & 7 & $4(36)$ & $4.50(3.51)$ \\
\hline Disputing unhelpful cognitions & $7(47)$ & $13(76)$ & $5(36)$ & $5.00(2.00)$ & $7(47)$ & $6.86(2.27)$ \\
\hline Relaxation/meditation practice & $-\cdots$ & \begin{tabular}{|l|l}
---- \\
\end{tabular} & $9(64)$ & $6.33(2.12)$ & $10(67)$ & $8.5(1.35)$ \\
\hline \multicolumn{7}{|c|}{ Particpants' self-reported changes in metacognition regarding decision-making style } \\
\hline $\begin{array}{l}\text { As a result of using the package, } \\
\text { would you say that you are more } \\
\text { aware of the possibility that your } \\
\text { emotions might impact on your } \\
\text { decision? } \\
\text { Yes / No }\end{array}$ & --- & 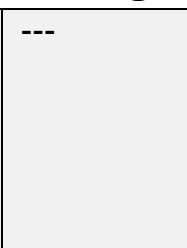 & $\begin{array}{l}\text { 79\% Yes } \\
(1 \text { Missing) }\end{array}$ & --- & $100 \%$ Yes & --- \\
\hline $\begin{array}{l}\text { As a result of using the package, } \\
\text { would you say that you are more } \\
\text { aware of when you are making } \\
\text { heuristic decisions? } \\
\text { Yes / No }\end{array}$ & --- & --- & $\begin{array}{l}57 \% \text { Yes } \\
\text { (3 missing) }\end{array}$ & --- & $87 \%$ Yes & --- \\
\hline
\end{tabular}




\begin{tabular}{|c|c|c|c|c|c|c|}
\hline $\begin{array}{l}\text { As a result of using the package, } \\
\text { would you say you were more } \\
\text { conscious of your overall } \\
\text { decision-making style? } \\
\text { Yes / No }\end{array}$ & $\begin{array}{l}60 \% \text { Yes } \\
(4 \text { missing] })\end{array}$ & $76 \%$ Yes & $\begin{array}{l}64 \% \text { Yes } \\
(2 \text { missing })\end{array}$ & --- & $87 \%$ Yes & --- \\
\hline $\begin{array}{l}\text { As a result of using the package, } \\
\text { would you say your decision- } \\
\text { making style has changed? } \\
\text { Yes / No }\end{array}$ & $\begin{array}{l}20 \% \text { Yes } \\
(5 \text { missing })\end{array}$ & $41 \%$ Yes & $\begin{array}{l}36 \% \\
\text { Yes } \\
\text { (3 missing) }\end{array}$ & --- & $\begin{array}{l}47 \% \text { Yes } \\
(1 \mathrm{missing})\end{array}$ & --- \\
\hline \multicolumn{7}{|c|}{ Particpants' overall evaluation of the programme } \\
\hline $\begin{array}{l}\text { Overall, would you say this CPD } \\
\text { has been helpful? } \\
\text { Very helpful / Somewhat / Not all } \\
\text { that helpful / Unhelpful }\end{array}$ & $\begin{array}{l}10(67) \text { Very } \\
10(7) \\
\text { somewhat }\end{array}$ & $\begin{array}{l}9 \text { (53) Very } 8 \\
\text { (47) somewhat }\end{array}$ & $\begin{array}{l}1(7) \text { Very } \\
10(14) \\
\text { somewhat } \\
(1 \text { missing })\end{array}$ & --- & $\begin{array}{l}7 \text { (47) Very } \\
8 \text { (53) } \\
\text { Somewhat }\end{array}$ & --- \\
\hline
\end{tabular}

